\title{
Combined aberrant expression of N-Myc downstream-regulated gene 2 and CD24 is associated with disease-free survival and overall survival in patients with hepatocellular carcinoma
}

Bing $\mathrm{Li}^{1,2}$, Qing Shao ${ }^{2}$, Dong $\mathrm{Ji}^{2}$, Fan $\mathrm{Li}^{2}$, Xiaodong Guo ${ }^{2}$ and Guofeng Chen ${ }^{2 *}$

\begin{abstract}
Background: N-Myc downstream-regulated gene 2 (NDRG2), as a tumor suppressor, has been demonstrated to inhibit tumor invasion and migration of hepatocellular carcinoma (HCC) by reducing the expression of CD24, which has been identified as a prognostic factor for HCC patients. However, the clinical significance of combined NDRG2 and CD24 expression in HCC remains unclear. Thus, the aim of the current study was to investigate the relationship of NDRG2 and CD24 expression with clinicopathological parameters and patients' survival.
\end{abstract}

Methods: Immunohistochemistry was performed to detect the expression and subcellular localizations of NDRG2 and CD24 proteins in 130 pairs of HCC and adjacent nonneoplastic liver tissues.

Results: NDRG2 protein was strongly expressed in the cytoplasm and plasma membrane of hepatocytes in adjacent nonneoplastic liver tissues, whereas its immunostaining was weak or negative in HCC tissues. In contrast, CD24 protein exhibited the cytoplasm immunostaining in tumor cells of HCC tissues but showed negative expression in adjacent nonneoplastic liver tissues. The statistical analysis also showed that the expression levels of NDRG2 and CD24 proteins in HCC tissues were respectively lower and higher than those in adjacent nonneoplastic liver tissues significantly (both $\mathrm{P}<0.001$ ). In addition, there was an inverse correlation between NDRG2 expression and CD24 expression in HCC tissues ( $P=0.02)$. Moreover, combined NDRG2 downregulation and CD24 upregulation (NDRG2-low/CD24-high) more frequently occurred in HCC tissues with high serum AFP $(P=0.03)$, advanced tumor stage $(P=0.001)$ and high tumor grade $(P=0.02)$. Furthermore, HCC patients with NDRG2-low/CD24-high expression showed shortest 5-year disease-free survival and 5-year overall survival (both $P<0.001$ ) of four groups (NDRG2-low/ CD24-high, NDRG2-low/CD24-low, NDRG2-high/CD24-high, NDRG2-high/CD24-low). Of note, the multivariate survival analysis showed that the combined aberrant expression of NDRG2 and CD24 proteins was an independent prognostic factor for both 5-year disease-free survival and 5-year overall survival (both $P=0.01$ ) in HCC.

Conclusions: These findings suggest that the downregulation of NDRG2 combined with the upregulation of CD24 may play a synergistic role in the occurrence and progression of HCC. A combined detection of NDRG2/CD24 expression may benefit us in determining the prognosis in patients with HCC.

Virtual Slides: The virtual slide(s) for this article can be found here: http://www.diagnosticpathology.diagnomx.eu/vs/ 13000_2014_209

Keywords: N-Myc downstream-regulated gene 2, CD24, Hepatocellular carcinoma, Disease-free survival, Overall survival

\footnotetext{
*Correspondence: gfchen302@163.com

${ }^{2}$ Liver Fibrosis Diagnosis and Treatment Center, Beijing 302 Hospital, Beijing 100039, China

Full list of author information is available at the end of the article
}

\section{Biomed Central}

(c) 2014 Li et al.; licensee BioMed Central Ltd. This is an Open Access article distributed under the terms of the Creative Commons Attribution License (http://creativecommons.org/licenses/by/4.0), which permits unrestricted use, distribution, and reproduction in any medium, provided the original work is properly credited. The Creative Commons Public Domain Dedication waiver (http://creativecommons.org/publicdomain/zero/1.0/) applies to the data made available in this article, unless otherwise stated. 


\section{Background}

Hepatocellular carcinoma (HCC), as one of the most common malignancies in the developing countries, has become the third leading cause of cancer-related deaths globally [1]. The incidence of HCC is still increasing in the developing countries. Annually, more than 700,000 new cases are diagnosed worldwide and also unfortunately more than 600,000 deaths are attributed to this cancer [2]. HCC is highly lethal because of its aggressive metastasis and an advanced stage at the time of diagnosis. The five-year survival rate of this cancer is merely 7\% [3]. Liver transplantation and surgical resection remain the cornerstone of curative therapies, which can improve the chances of survival of patients with HCC [4]. Since the diagnosis at early stage of HCC offers the only hope for curative therapies, it is of utmost importance to screen high-risk patients effectively. With the increasing understanding of tumor biology of HCC, recent studies have identified more and more molecular markers with high sensitivity and specificity for diagnosis and prognosis in patients with HCC.

$\mathrm{N}$-myc downstream-regulated gene 2 (NDRG2) belongs to the NDRG family containing four members, NDRG1, NDRG2, NDRG3 and NDRG4, the amino acid sequence homology among which is $57-65 \%$, suggesting the conserved function of this family [5]. NDRG2 is localized on chromosome 14q11.2 and encodes a protein of $41 \mathrm{kDa}$ weight [6]. Physiologically, it is involved in cell proliferation, differentiation, and neurodegeneration, and is extensively expressed in cells of the brain, the liver, the kidneys, the salivary glands and muscles, but is almost undetectable in the thymus, the bone marrow and leukocytes of peripheral blood [7]. Under the pathological conditions, NDRG2 functions as a tumor suppressor gene and is downregulated in a variety of human cancer types, such as glioblastoma, thyroid cancer, breast cancer, HCC, gastric cancer, colorectal cancer and prostate cancer [8-14]. In addition, it has been demonstrated to be implicated in the process of apoptosis in response to DNA lesion, and acts as an inhibitor of cellular proliferation. Several in vitro studies showed a reduced cell growth when NDRG2 was over-expressed in cell-lines lacking endogenous expression [15]. Moreover, the upregulation of NDRG2 has been found to be associated with a favorable prognosis in several human malignancies, such as high-grade gliomas, gastric cancer and HCC [16-18]. These findings suggest that NDRG2 may play a crucial role in suppressing carcinogenesis.

CD24, as a small heavily glycosylated mucin-like glycosyl-phosphatidylinositol (GPI)-linked cell surface protein, is attached to the cell membrane by a glycosylphosphatidylinositol anchor [19]. It is not only expressed in developing or regenerating tissue but also in granulocytes, pre-B cells, keratinocytes, and renal tubules, and plays an important roles in cell selection and maturation during hematopoiesis [20]. Under the pathological conditions, CD24, as a member of Ral GTPases signaling which mediates the transformation, tumorigenesis, and tumor progression, functions as a Ral-regulated target and is involved in cell adhesion and tumor metastasis [21]. Its upregulation has been observed not only in haematologic malignancies, but also in various solid tumors, such as glioma, nasopharyngeal carcinoma, breast cancer, small cell lung carcinoma, HCC, renal cell carcinoma, ovarian cancer, bladder carcinoma and prostate cancer [22-30]. The overexpression of CD24 is usually tied with a more aggressive progression of tumor. More interestingly, it has been identified as a novel prognostic marker in a variety of human malignancies, suggesting its significant impact on patient outcome.

Previous studies has reported that NDRG2 may reduce the metastatic potential of cancer cells by regulating the expression of CD24. Especially in HCC, Zheng et al. [18] reported that NDRG2 expression was negatively correlated with tumor malignancy and could inhibit HCC cell adhesion, migration and invasion by regulating the expression of CD24, which has been demonstrated by Yang et al. [26] to be a novel predictor for poor prognosis of HCC patients after surgery. However, the clinical significance of combined expression of NDRG2 and CD24 in HCC remains unclear. Thus, the aim of the current study was to investigate the relationship of NDRG2 and CD24 expression with clinicopathological parameters and patients' survival.

\section{Methods}

\section{Patients and tissue samples}

This study was approved by the Research Ethics Committee of 302nd Hospital of PLA, Beijing, China. Written informed consent was obtained from all of the patients. All specimens were handled and made anonymous according to the ethical and legal standards.

In this retrospective study, a total of 130 patients with primary HCC who underwent a curative liver resection at the 302nd Hospital of PLA, Beijing, China, were enrolled. One hundred and thirty HCC and adjacent nonneoplastic liver tissues obtained from these patients were retrieved from the tissue bank of the Department of Pathology in the 302nd Hospital of PLA. These patients were diagnosed as HCC March 2001 and February 2006. None of the patients recruited in this study had chemotherapy or radiotherapy before the surgery. HCC diagnosis was based on World Health Organization (WHO) criteria. Tumor differentiation was defined according to the Edmondson grading system. Liver function was assessed using the Child-Pugh scoring system. Tumor staging was determined according to the sixth edition of the tumornode-metastasis (TNM) classification of the International 
Union against Cancer. The clinicopathological features of 130 patients are summarized in Table 1.

The median follow-up period of 130 patients with primary HCC was 8.6 years. Postoperative surveillance included routine clinical and laboratory examinations every third month, computed tomography scans of the abdomen, and radiographs of the chest every third month. After 5 years, the examination interval was extended to 12 months.

\section{Immunohistochemistry analysis}

Immunohistochemistry was performed to detect the expression patterns and the subcellular localizations of NDRG2 and CD24 proteins in HCC and adjacent nonneoplastic liver tissues following the protocol of our previous study [31-33]. The primary antibodies: mouse anti-human NDRG2 monoclonal antibody (Neomarkers, Clone 24C02, 1:100 dilution, Fremont, CA, US, 1:500

Table 1 Clinicopathological characteristics of 130 patients with hepatocellular carcinoma

\begin{tabular}{|c|c|c|c|}
\hline $\begin{array}{l}\text { Clinicopathological } \\
\text { characteristics }\end{array}$ & Case & Male $(\mathrm{N}=96)$ & Female $(n=34)$ \\
\hline \multicolumn{4}{|l|}{ Age (years) } \\
\hline$\leq 50$ & 72 & 52 & 20 \\
\hline$>50$ & 58 & 44 & 14 \\
\hline \multicolumn{4}{|l|}{ Serum AFP } \\
\hline Positive & 72 & 54 & 18 \\
\hline Negative & 58 & 42 & 16 \\
\hline \multicolumn{4}{|l|}{ Tumor stage } \\
\hline $\mathrm{T} 1$ & 23 & 19 & 4 \\
\hline $\mathrm{T} 2$ & 40 & 30 & 10 \\
\hline T3 & 52 & 37 & 15 \\
\hline T4 & 15 & 10 & 5 \\
\hline \multicolumn{4}{|l|}{ Tumor grade } \\
\hline G1 & 31 & 21 & 10 \\
\hline G2 & 76 & 57 & 19 \\
\hline G3 & 23 & 18 & 5 \\
\hline \multicolumn{4}{|l|}{ Growth pattern } \\
\hline Trabecular & 101 & 76 & 25 \\
\hline Nontrabecular & 29 & 20 & 9 \\
\hline \multicolumn{4}{|l|}{ Cirrhosis } \\
\hline Yes & 86 & 63 & 23 \\
\hline No & 44 & 33 & 11 \\
\hline \multicolumn{4}{|c|}{ Underlying liver disease } \\
\hline Alcoholic & 25 & 16 & 9 \\
\hline Hepatitis B & 49 & 39 & 10 \\
\hline Hepatitis C & 35 & 26 & 9 \\
\hline Unknown & 21 & 15 & 6 \\
\hline
\end{tabular}

dilution, Santa Cruz, CA, USA) and mouse anti-human CD24 monoclonal antibody (Neomarkers, Clone 24C02, 1:100 dilution, Fremont, CA, US). The specificities of these two primary antibodies have been validated by Gao et al. [34] and Bircan et al. [35]. Secondary antibody for the detection of primary antibody: anti-mouse IgG (\#sc-2025, Santa Cruz Biotechnology, Inc. USA). The negative controls were processed in a similar manner with PBS instead of primary antibody. The positive NDRG2 and CD24 expressions confirmed by western blotting were used as positive controls for immunostaining.

The results of immunohistochemistry were evaluated by two independent experienced pathologists, who were blinded to the clinicopathological data and clinical outcomes of the patients. Their scores were compared and any discrepant scores were re-examined by both pathologists to reach a consensus score. The number of positive-staining cells in ten representative microscopic fields was counted and the percentage of positive cells was calculated. The percentage scoring of positive tumor cells was as follows: 0 (0\%), 1 (1-10\%), 2 (11-50\%) and 3 $(>50 \%)$. The staining intensity was visually scored and stratified as follows: 0 (negative), 1 (weak), 2 (moderate) and 3 (strong). A final score was obtained for each case by multiplying the percentage and the intensity score. Therefore, tumors with a multiplied score exceeding median of total score for NDRG2 (median $=2.39$ ) or CD24 (median $=4.16)$ were deemed to be high expressions of NDRG2 or CD24; all other scores were considered to be low expressions of NDRG2 or CD24.

\section{Statistical analysis}

Statistical analysis was performed by the software of SPSS version13.0 for Windows (SPSS Inc, IL, USA) and SAS 9.1 (SAS Institute, Cary, NC). The differences in the means of NDRG2 and CD24 expression levels between HCC and adjacent nonneoplastic liver tissues were determined using the paired $t$ test. The chi-squared test was used to show differences in categorical variables. Correlations between CREB and PCREB expression were calculated using Spearman's correlation. The differences in patient survival were determined by the Kaplan-Meier method and the log-rank test, respectively. A Cox regression analysis (proportional hazard model) was performed for the multivariate analyses of prognostic factors. Differences were considered statistically significant when $\mathrm{P}$ was less than 0.05 .

\section{Results}

Expression patterns and subcellular localizations of NDRG2 and CD24 in HCC and adjacent nonneoplastic liver tissues

Expression patterns and subcellular localizations of NDRG2 and CD24 proteins in 130 self pairs of HCC and 
adjacent nonneoplastic liver tissues were respectively observed by the immunohistochemistry analysis. Representative images are shown in Figure 1. The immunostainings of both NDRG2 and CD24 proteins varied in the intensity and the percentage of positive tumor cells. As shown in Figure 1A and B, NDRG2 protein was strongly expressed in the cytoplasm and plasma membrane of hepatocytes in adjacent nonneoplastic liver tissues, whereas its immunostaining was weak or negative in HCC tissues. In contrast, CD24 protein exhibited the cytoplasm immunostaining in tumor cells of HCC tissues but showed negative expression in adjacent nonneoplastic liver tissues (Figure 1D and E). The statistical analysis also showed that the expression levels of NDRG2 and CD24 proteins in HCC tissues were respectively lower and higher than those in adjacent nonneoplastic liver tissues significantly (both $\mathrm{P}<0.001$, Figure $\mathrm{C}$ and $\mathrm{F}$ ).

In addition, based on the scoring system used in the present study, $30(23.08 \%)$ cases were both high expression of NDRG2 and CD24, 28 (21.54\%) cases were both low expression of NDRG2 and CD24, 22 (16.92\%) cases were NDRG2-high and CD24-low expression, and 50 (38.46\%) cases were NDRG2-low and CD24-high expression. Moreover, there was an inverse correlation between
NDRG2 expression and CD24 expression in HCC tissues $(\mathrm{r}=0.45, \mathrm{P}=0.02$, Figure 2$)$.

\section{Association between combined aberrant expression of NDRG2 and CD24 and the clinicopathological characteristics of $\mathrm{HCC}$}

The association between combined aberrant expression of NDRG2 and CD24 (NDRG2/CD24) and the clinicopathological characteristics of patients with $\mathrm{HCC}$ was summarized in Table 2. Combined NDRG2 downregulation and CD24 upregulation (NDRG2-low/CD24-high) more frequently occurred in HCC tissues with high serum AFP $(P=0.03)$, advanced tumor stage $(P=0.001)$ and high tumor grade $(\mathrm{P}=0.02)$.

\section{Prognostic implications of combined aberrant expression of NDRG2 and CD24 in HCC}

Five-year disease-free survival was observed in 30 (23.08\%) patients, whereas in 100 (76.92\%) patients, disease recurred, and $88(67.69 \%)$ even died during a 5-year follow-up period. The association between combined aberrant expression of NDRG2 and CD24 (NDRG2/CD24) and the survival rates were tested by the method of Kaplan-Meier. The Chi-square value by Log Rank (Mantel-Cox) indicated a significant difference among different groups with regard

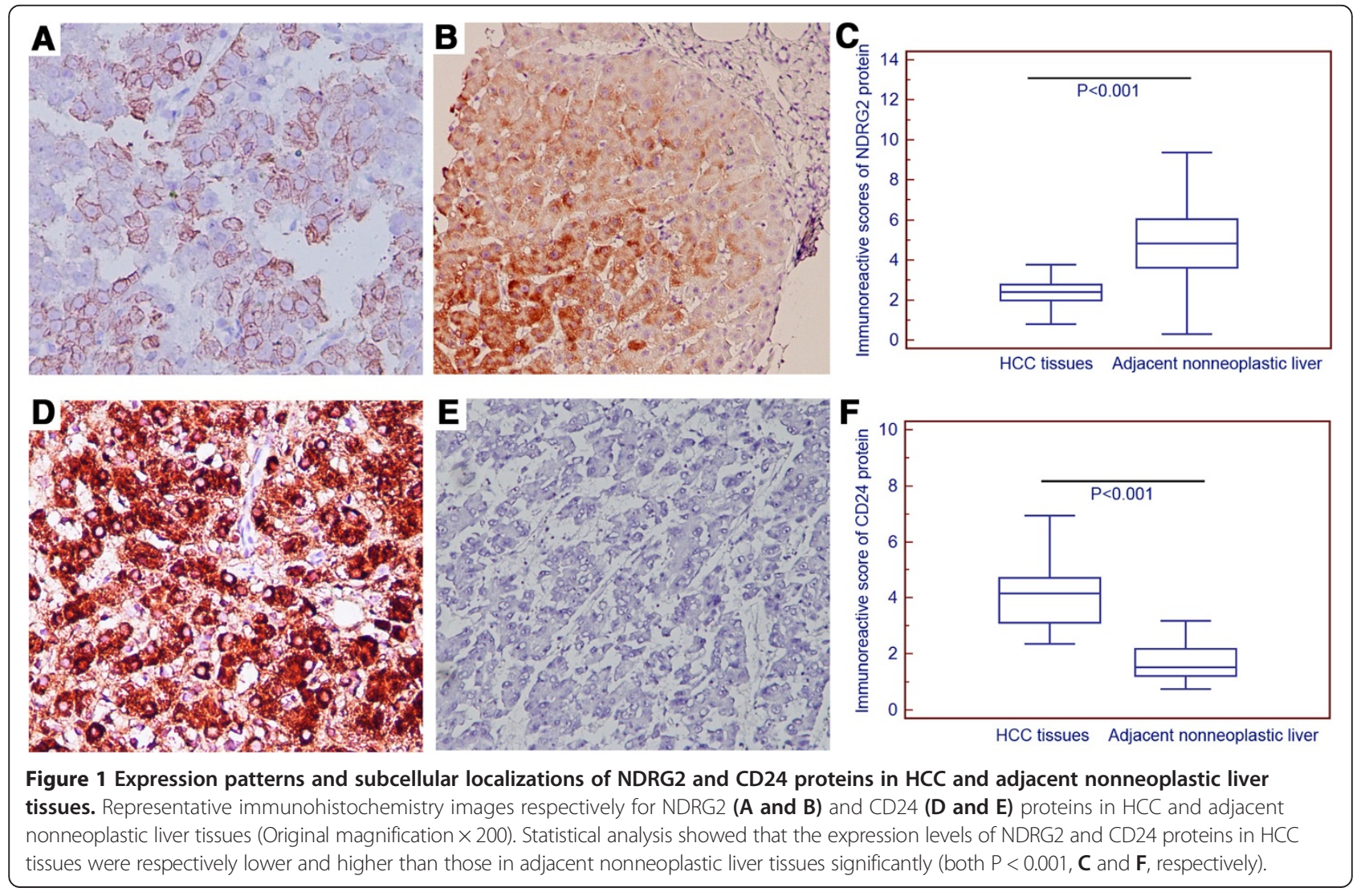




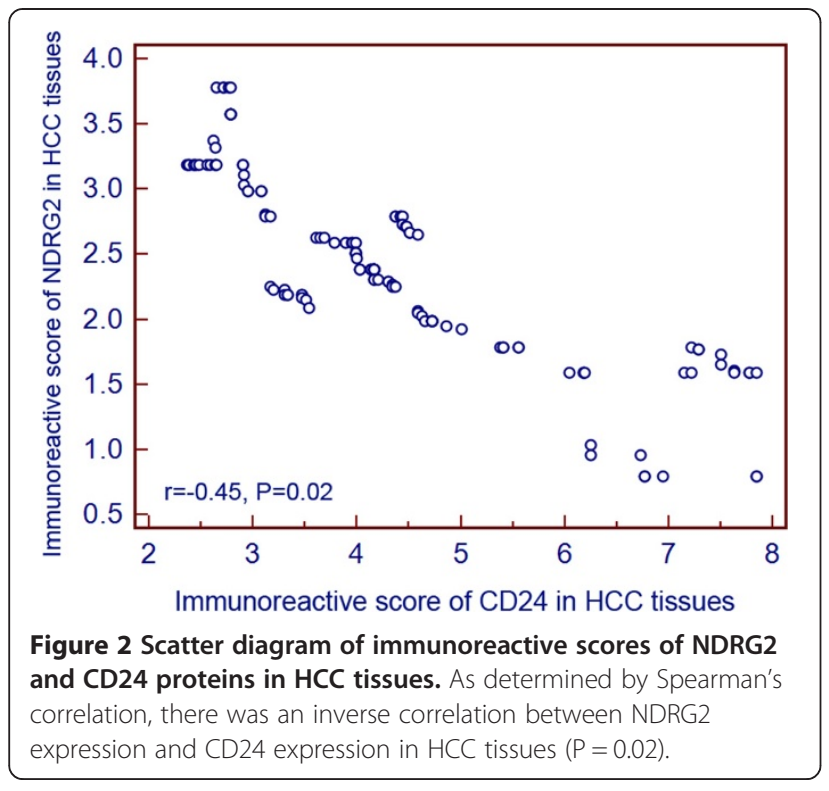

to the conjoined expression status of NDRG2/CD24 (Figure $3 \mathrm{~A}$ and $\mathrm{B}$ ). The results by pairwise comparisons showed that the statistically significant difference of disease-free survival and overall survival existed between NDRG2-low/CD24-high patients and any of other three groups (both $\mathrm{P}<0.001$ ). In all four groups, NDRG2-low/ CD24-high patients had the poorest prognosis.

Furthermore, in a multivariate Cox model, including serum AFP, tumor stage, tumor grade, presence of cirrhosis, and NDRG2/CD24 expression, we found that tumor stage $(\mathrm{P}=0.009$ and 0.01 , respectively, Table 3$)$ and NDRG2/CD24 expression (both $\mathrm{P}=0.01$, Table 3) were independent poor prognostic factors for both 5-year disease-free survival and 5-year overall survival in HCC.

\section{Discussion}

It is of great challenge for clinicians and basic scientists to find out the molecular markers associated with the progression and prognosis of HCC. In the current study, the clinical significance of combined aberrant expression of NDRG2 and CD24 in HCC was evaluated.

Tumor progression and metastasis of HCC are a multistep process including cell adhesion to the extracellular matrix (ECM), proteolytic digestion of ECM, invasion into the lymph and blood vessels, and migration [36]. NDRG2 has been identified as one of tumor suppressor genes in the mechanism of metastasis formation. An increasing number of studies have performed to analyze the expression levels of NDRG2 in various neoplasms. Zhao et al. [9] revealed a decrease of NDRG2 expression in thyroid carcinomas. Deng et al. [8] indicated that the reduced NDRG2 expression in approximately $60 \%$ of gliomas versus the expression levels in normal brain tissue. Liang et al. [10] reported that the lack of NDRG2 might be associated with oncogenic
Table 2 Association of the combined aberrant expression of NDRG2 and CD24 proteins with clinicopathological characteristics of 130 patients with hepatocellular carcinoma

\begin{tabular}{|c|c|c|c|}
\hline $\begin{array}{l}\text { Clinicopathological } \\
\text { characteristics }\end{array}$ & Case & NDRG2-low/CD24-high (n, \%) & $P$ \\
\hline \multicolumn{4}{|l|}{ Age (years) } \\
\hline$\leq 50$ & 72 & $28(38.89)$ & \multirow[t]{2}{*}{ NS } \\
\hline$>50$ & 58 & $22(37.93)$ & \\
\hline \multicolumn{4}{|l|}{ Gender } \\
\hline Male & 96 & $35(36.46)$ & \multirow[t]{2}{*}{ NS } \\
\hline Female & 34 & $15(44.12)$ & \\
\hline \multicolumn{4}{|l|}{ Serum AFP } \\
\hline Positive & 72 & $34(47.22)$ & \multirow[t]{2}{*}{0.03} \\
\hline Negative & 58 & $16(27.59)$ & \\
\hline \multicolumn{4}{|l|}{ Tumor stage } \\
\hline $\mathrm{T} 1$ & 23 & $0(0)$ & \multirow[t]{4}{*}{0.001} \\
\hline $\mathrm{T} 2$ & 40 & $10(25.00)$ & \\
\hline T3 & 52 & $25(48.08)$ & \\
\hline $\mathrm{T} 4$ & 15 & $15(100.00)$ & \\
\hline \multicolumn{4}{|l|}{ Tumor grade } \\
\hline G1 & 31 & $5(16.13)$ & \multirow[t]{3}{*}{0.02} \\
\hline $\mathrm{G} 2$ & 76 & $30(39.47)$ & \\
\hline G3 & 23 & $15(65.22)$ & \\
\hline \multicolumn{4}{|l|}{ Growth pattern } \\
\hline Trabecular & 101 & $40(39.60)$ & \multirow[t]{2}{*}{ NS } \\
\hline Nontrabecular & 29 & $10(34.48)$ & \\
\hline \multicolumn{4}{|l|}{ Cirrhosis } \\
\hline Yes & 86 & $35(40.70)$ & \multirow[t]{2}{*}{ NS } \\
\hline No & 44 & $15(34.09)$ & \\
\hline \multicolumn{4}{|l|}{ Underlying liver disease } \\
\hline Alcoholic & 25 & $10(40.00)$ & \multirow[t]{4}{*}{ NS } \\
\hline Hepatitis B & 49 & $20(40.82)$ & \\
\hline Hepatitis C & 35 & $10(28.57)$ & \\
\hline Unknown & 21 & $10(47.62)$ & \\
\hline
\end{tabular}

Note: 'NS' refers to the differences among groups have no statistical significance.

properties through the loss of its role as a tumor suppressor, and that NDRG2 was an independent poor prognostic factor predicting survival in renal cell carcinoma. Lorentzen et al. [11] found that the expression of NDRG2 mRNA was reduced in breast cancer. Especially in HCC, Zheng et al. [18] observed the downregulation of NDRG2 which can inhibit ECM-based, Rho-driven tumor cell invasion and migration and thereby play important roles in suppressing tumor metastasis according to the data of Lee et al. [12]. Consistent with these findings, we in the current study also confirmed the reduced expression of NDRG2 at protein level in HCC tissues compared 

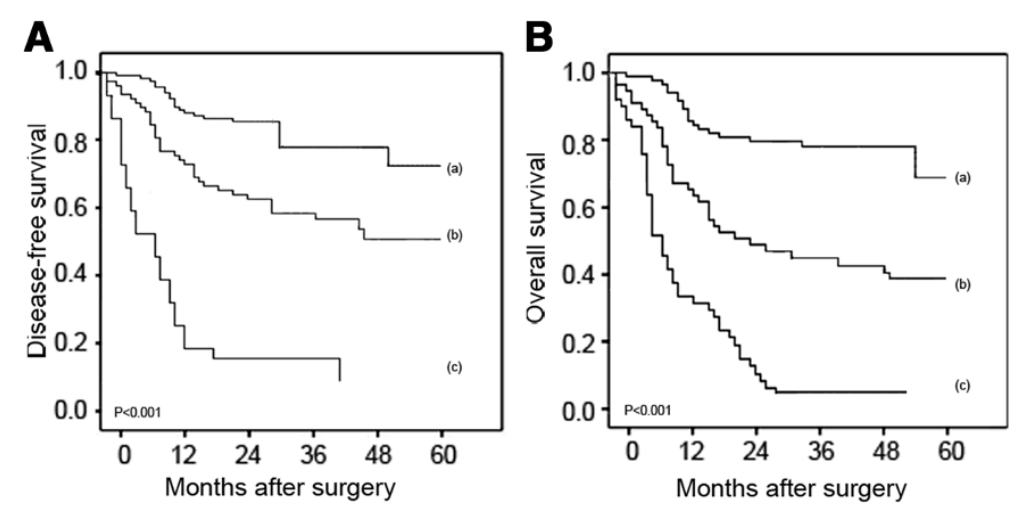

Figure 3 Kaplan-Meier disease-free survival (A) and overall survival (B) curves for 4 groups of NDRG2 and CD24 expression in HCC tissues. Patients with NDRG2-low/CD24-high expression profile had the worst outcome for both disease-free survival and overall survival among the 4 groups. Pairwise comparisons showed that the statistically significant difference of survival rates existed between NDRG2-low/CD24-high cases and any of other three groups. Note: 'a' refers to NDRG2-high/CD24-low; 'b' refers to NDRG2-low/CD24-low and NDRG2-high/CD24-high; 'c' refers to NDRG2-low/CD24-high.

with adjacent nonneoplastic liver tissues, suggesting its implication in the tumorigenesis of HCC.

During the process of tumor metastasis, it is of particular importance to induce tumor cells to bind with platelets in the blood stream. The enhancement of the ability of tumor to bind to endothelial cells may also be beneficial for metastasis [37]. Because it has been identified as a ligand of P-selectin, an adhesion receptor on activated endothelial cells and platelets, CD24 functionally enhances the metastatic potential of malignant-cells. Kim et al. [24] demonstrated that CD24 expression was a significant predictor of distant metastasis for patients undergoing curative resection followed by adjuvant chemoradiotherapy especially for node-positive extrahepatic bile duct cancer. Takahashi et al. [25] indicated that the overexpression of CD24 was markedly associated with lymph node metastasis of gastric cancer. Thomas et al. [27] identified CD24 as an effector of HIF-1-driven primary tumor growth and metastasis. Zhu et al. [28] also determined the overexpression of CD24 as an independent factor associated with tumor metastasis of epithelial ovarian cancer. Especially in HCC, Yang et al. [26] found that CD24 was overexpressed in the highly metastatic HCC cell line and in tumor tissues of patients with recurrent tumors. They also revealed that CD24 was a significant predictor for overall survival and relapse-free survival. CD24 expression was correlated with poor prognosis independent of $\alpha$-fetoprotein, tumor-node-metastasis stage, and Edmondson stage. In line with these findings, our data showed the upregulation of CD24 in HCC tissues compared with adjacent nonneoplastic liver tissues, implying that CD24 may play a role in the development of HCC.

Since the recent studies have found the regulatory effect of NDRG2 on CD24 in several cancer cells, we hypothesized that the combined aberrant expression of NDRG2 and CD24 might be associated with tumor progression and prognosis in patients with HCC. Interestingly, our data validated this hypothesis. We found that the combined NDRG2 downregulation and CD24 upregulation was markedly associated with the aggressive clinicopathological characteristics of HCC, including serum AFP level, tumor stage and tumor grade. More importantly, we analyzed the association of NDRG2/CD24 conjoined expression with the prognosis of HCC. Significant difference of prognosis was found among four different statuses of NDRG2/CD24 co-expression. The patients with NDRG2-high/CD24-low had the best outcome, while the NDRG2-low/CD24-high had the worst. Multivariate analysis revealed that the NDRG2/CD24

Table 3 Multivariate survival analysis of five-year overall and disease-free survival in 130 patients with hepatocellular carcinoma

\begin{tabular}{|c|c|c|c|c|c|c|}
\hline \multirow[t]{2}{*}{ Features } & \multicolumn{3}{|c|}{ Five-year overall survival } & \multicolumn{3}{|c|}{ Five-year disease-free survival } \\
\hline & $\mathrm{HR}$ & $95 \% \mathrm{Cl}$ & $\mathbf{P}$ & HR & $95 \% \mathrm{Cl}$ & $\mathbf{P}$ \\
\hline Serum AFP & 1.931 & $0.685-4.056$ & 0.063 & 1.953 & $0.615-4.273$ & 0.062 \\
\hline Tumor stage & 2.879 & $1.366-5.196$ & 0.009 & 2.686 & $1.386-6.009$ & 0.01 \\
\hline Tumor grade & 1.563 & $0.609-4.088$ & 0.081 & 1.551 & $0.607-4.466$ & 0.086 \\
\hline Presence of cirrhosis & 1.919 & $0.738-4.102$ & 0.063 & 1.921 & $0.793-4.219$ & 0.062 \\
\hline NDRG2/CD24 expression & 5.916 & $1.363-12.698$ & 0.01 & 5.268 & $1.256-11.088$ & 0.01 \\
\hline
\end{tabular}


co-expression profile was an independent prognostic indicator for both disease-free survival and overall survival of patients with HCC. Further investigation extended in much more cases is in need to evaluate the potential application value of NDRG2/CD24 co-expression as dependent or independent prognosis factor of $\mathrm{HCC}$ in clinical setting.

\section{Conclusion}

In conclusion, our data in the current study suggest that the downregulation of NDRG2 combined with the upregulation of CD24 may play a synergistic role in the occurrence and progression of HCC. A combined detection of NDRG2/CD24 expression may benefit us in determining the prognosis in patients with $\mathrm{HCC}$.

\section{Competing interests}

The authors declare that they have no competing interests.

\section{Authors' contributions}

LB participated in the study design, carried out the immunohistochemistry analysis and drafted the manuscript. SQ and JD participated in the immunohistochemistry analysis. LF and GX performed the statistical analysis. CG conceived of the study, and participated in its design and coordination. All authors read and approved the final manuscript.

\section{Author details}

${ }^{1}$ Medical School of Chinese PLA, Beijing 100853, China. ${ }^{2}$ Liver Fibrosis Diagnosis and Treatment Center, Beijing 302 Hospital, Beijing 100039, China.

Received: 26 August 2014 Accepted: 8 October 2014

Published online: 23 October 2014

\section{References}

1. Jemal A, Bray F, Center MM, Ferlay J, Ward E, Forman D: Global cancer statistics. CA Cancer J Clin 2011, 61:69-90.

2. Kiyosawa K, Umemura T, Ichijo T, Matsumoto A, Yoshizawa K, Gad A, Tanaka E: Hepatocellular carcinoma: recent trends in Japan. Gastroenterology 2004, 127:S17-S26.

3. Nguyen VT, Law MG, Dore GJ: Hepatitis B-related hepatocellular carcinoma: epidemiological characteristics and disease burden. J Viral Hepat 2009, 16:453-463.

4. Dhanasekaran R, Limaye A, Cabrera R: Hepatocellular carcinoma: current trends in worldwide epidemiology, risk factors, diagnosis, and therapeutics. Hepat Med 2012, 4:19-37.

5. Mordalska A, Latek J, Ferenc T, Pomorski L, Gałecka E, Zygmunt A, Lewiński A: Evaluation of NDRG2 gene expression in primary papillary thyroid carcinoma and in metastases of this neoplasm to regional lymph nodes. Thyroid Res 2010, 3:6.

6. Kim MJ, Lim J, Yang Y, Lee MS, Lim JS: N-myc downstream-regulated gene 2 (NDRG2) suppresses the epithelial-mesenchymal transition (EMT) in breast cancer cells via STAT3/Snail signaling. Cancer Lett 2014, 354:33-42.

7. Liu J, Zhang J, Wang X, Li Y, Chen Y, Li K, Zhang J, Yao L, Guo G: HIF-1 and NDRG2 contribute to hypoxia-induced radioresistance of cervical cancer Hela cells. Exp Cell Res 2010, 316:1985-1993.

8. Deng Y, Yao L, Chau L, Ng SS, Peng Y, Liu X, Au WS, Wang J, Li F, Ji S, Han H, Nie X, Li Q, Kung HF, Leung SY, Lin MC: N-Myc downstream-regulated gene 2 (NDRG2) inhibits glioblastoma cell proliferation. Int J Cancer 2003, 106:342-347.

9. Zhao H, Zhang J, Lu J, He X, Chen C, Li X, Gong L, Bao G, Fu Q, Chen S, Lin W, Shi H, Ma J, Liu X, Ma Q, Yao L: Reduced expression of N-Myc downstream-regulated gene 2 in human thyroid cancer. BMC Cancer 2008, 8:303.

10. Liang ZL, Kang K, Yoon S, Huang SM, Lim JS, Kim JM, Lim JS, Lee HJ: NDRG2 is involved in the oncogenic properties of renal cell carcinoma and its loss is a novel independent poor prognostic factor after nephrectomy. Ann Surg Oncol 2012, 19:2763-2772.
11. Lorentzen A, Lewinsky RH, Bornholdt J, Vogel LK, Mitchelmore C: Expression profile of the N-myc Downstream Regulated Gene 2 (NDRG2) in human cancers with focus on breast cancer. BMC Cancer 2011, 11:14.

12. Lee DC, Kang YK, Kim WH, Jang YJ, Kim DJ, Park IY, Sohn BH, Sohn HA, Lee HG, Lim JS, Kim JW, Song EY, Kim DM, Lee MN, Oh GT, Kim SJ, Park KC, Yoo HS, Choi JY, Yeom Yl: Functional and clinical evidence for NDRG2 as a candidate suppressor of liver cancer metastasis. Cancer Res 2008, 68:4210-4220.

13. Feng $L, X i e Y, Z$ hang $H, W u Y$ : Down-regulation of NDRG2 gene expression in human colorectal cancer involves promoter methylation and microRNA-650. Biochem Biophys Res Commun 2011, 406:534-538.

14. Yu C, Wu G, Dang N, Zhang W, Zhang R, Yan W, Zhao Y, Gao L, Wang Y, Beckwith N, Yuan J, Yao L: Inhibition of N-myc downstream-regulated gene 2 in prostatic carcinoma. Cancer Biol Ther 2011, 12:304-313.

15. Yao L, Zhang J, Liu X: NDRG2: a Myc-repressed gene involved in cancer and cell stress. Acta Biochim Biophys Sin (Shanghai) 2008, 40:625-635.

16. Liu N, Wang L, Liu X, Yang Q, Zhang J, Zhang W, Wu Y, Shen L, Zhang Y, Yang A, Han H, Zhang J, Yao L: Promoter methylation, mutation, and genomic deletion are involved in the decreased NDRG2 expression levels in several cancer cell lines. Biochem Biophys Res Commun 2007, 358:164-169.

17. Choi SC, Yoon SR, Park YP, Song EY, Kim JW, Kim WH, Yang Y, Lim JS, Lee HG: Expression of NDRG2 is related to tumor progression and survival of gastric cancer patients through Fas-mediated cell death. Exp Mol Med 2007, 39:705-714.

18. Zheng J, Li Y, Yang J, Liu Q, Shi M, Zhang R, Shi H, Ren Q, Ma J, Guo H, Tao Y, Xue Y, Jiang N, Yao L, Liu W: NDRG2 inhibits hepatocellular carcinoma adhesion, migration and invasion by regulating CD24 expression. BMC Cancer 2011, 251:1-9.

19. Kristiansen $G$, Sammar M, Altevogt P: Tumour biological aspects of CD24, a mucin-like adhesion molecule. J Mol Histol 2004, 35:255-262.

20. Cufi S, Vazquez-Martin A, Oliveras-Ferraros C, Martin-Castillo B, Vellon L, Menendez JA: Autophagy positively regulates the CD44(+) CD24(-/low) breast cancer stem-like phenotype. Cell Cycle 2011, 10:3871-3885.

21. Aigner S, Sthoeger ZM, Fogel M, Weber E, Zarn J, Ruppert M, Zeller Y, Vestweber D, Stahel R, Sammar M, Altevogt P: CD24, a mucin-type glycoprotein, is a ligand for P-selectin on human tumor cells. Blood 1997, 89:3385-3395.

22. Karran L, Jones M, Morley G, Van Noorden S, Smith P, Lampert I, Griffin BE: Expression of a B-cell marker, CD24, on nasopharyngeal carcinoma cells. Int J Cancer 1995, 60:562-566.

23. Sheridan C, Kishimoto H, Fuchs RK, Mehrotra S, Bhat-Nakshatri P, Turner CH, Goulet R Jr, Badve S, Nakshatri H: CD44+/CD24- breast cancer cells exhibit enhanced invasive properties: an early step necessary for metastasis. Breast Cancer Res 2006, 8:R59.

24. Kim HJ, Kim MJ, Ahn SH, Son BH, Kim SB, Ahn JH, Noh WC, Gong G: Different prognostic significance of CD24 and CD44 expression in breast cancer according to hormone receptor status. Breast 2011, 20:78-85.

25. Takahashi M, Nakajima M, Ogata H, Domeki Y, Ohtsuka K, Ihara K, Kurayama E, Yamaguchi S, Sasaki K, Miyachi K, Kato H: CD24 expression is associated with progression of gastric cancer. Hepatogastroenterology 2013, 60:653-658.

26. Yang XR, Xu Y, Yu B, Zhou J, Li JC, Qiu SJ, Shi YH, Wang XY, Dai Z, Shi GM, Wu B, Wu LM, Yang GH, Zhang BH, Qin WX, Fan J: CD24 is a novel predictor for poor prognosis of hepatocellular carcinoma after surgery. Clin Cancer Res 2009, 15:5518-5527.

27. Thomas S, Harding MA, Smith SC, Overdevest JB, Nitz MD, Frierson HF, Tomlins SA, Kristiansen G, Theodorescu D: CD24 is an effector of HIF-1-driven primary tumor growth and metastasis. Cancer Res 2012, 72:5600-5612.

28. Zhu J, Zhang G, Lu H: CD24, COX-2, and p53 in epithelial ovarian cancer and its clinical significance. Front Biosci (Elite Ed) 2012, 4:2745-2751.

29. Marmé F, Werft W, Walter A, Keller S, Wang X, Benner A, Burwinkel B, Sinn P, Hug S, Sohn C, Bretz N, Moldenhauer G, Rupp C, Rupp AK, Biakhov MY, Bottini A, Friedrichs K, Khailenko VA, Manikhas GM, Ruiz A, Sánchez-Rovira P, Santoro A, Segui MA, Villena C, Lichter P, Kristiansen G, Altevogt P, Schneeweiss A: CD24 Ala57Val polymorphism predicts pathologic complete response to sequential anthracycline- and taxane-based neoadjuvant chemotherapy for primary breast cancer. Breast Cancer Res Treat. 2011 In press.

30. Liu C, Zheng S, Shen H, Xu K, Chen J, Li H, Xu Y, Xu A, Chen B, Kaku H, Nasu Y, Kumon H, Huang P, Watanabe M: Clinical significance of CD24 as a predictor of bladder cancer recurrence. Oncol Lett 2013, 6:96-100. 
31. Guo X, Xiong L, Zou L, Zhao J: Upregulation of bone morphogenetic protein 4 is associated with poor prognosis in patients with hepatocellular carcinoma. Pathol Oncol Res 2012, 18:635-640.

32. Guo X, Xiong L, Sun T, Peng R, Zou L, Zhu H, Zhang J, Li H, Zhao J: Expression features of SOX9 associate with tumor progression and poor prognosis of hepatocellular carcinoma. Diagn Pathol 2012, 7:44.

33. Guo X, Xiong L, Zou L, Sun T, Zhang J, Li H, Peng R, Zhao J: L1 cell adhesion molecule overexpression in hepatocellular carcinoma associates with advanced tumor progression and poor patient survival. Diagn Pathol 2012, 7:96.

34. Gao L, Wu GJ, Liu XW, Zhang R, Yu L, Zhang G, Liu F, Yu CG, Yuan JL, Wang H Yao LB: Suppression of invasion and metastasis of prostate cancer cells by overexpression of NDRG2 gene. Cancer Lett 2011, 310:94-100.

35. Bircan S, Kapucuoglu N, Baspinar S, Inan G, Candir O: CD24 expression in ductal carcinoma in situ and invasive ductal carcinoma of breast: an immunohistochemistry-based pilot study. Pathol Res Pract 2006, 202:569-576.

36. Purcell WT, Rudek MA, Hidalgo M: Development of matrix metalloproteinase inhibitors in cancer therapy. Hematol Oncol Clin North Am 2002, 16:1189-1227.

37. Bendas G, Borsig L: Cancer cell adhesion and metastasis: selectins, integrins, and the inhibitory potential of heparins. Int J Cell Biol 2012, 2012:676731.

doi:10.1186/s13000-014-0209-5

Cite this article as: Li et al:: Combined aberrant expression of N-Myc downstream-regulated gene 2 and CD24 is associated with disease-free survival and overall survival in patients with hepatocellular carcinoma.

Diagnostic Pathology 2014 19:209.

\section{Submit your next manuscript to BioMed Central and take full advantage of:}

- Convenient online submission

- Thorough peer review

- No space constraints or color figure charges

- Immediate publication on acceptance

- Inclusion in PubMed, CAS, Scopus and Google Scholar

- Research which is freely available for redistribution 